\title{
Establish Cross-Border Warehousing and Improve the Competitiveness of E-Commerce
}

\author{
Fei Li, Jin Hong \\ The School of Management, University of Science and Technology of China, Hefei, China
}

Email address:

416693586@qq.com (Fei Li)

\section{To cite this article:}

Fei Li, Jin Hong. Establish Cross-Border Warehousing and Improve the Competitiveness of E-Commerce. International Journal of Economic Behavior and Organization. Vol. 6, No. 2, 2018, pp. 45-52. doi: 10.11648/j.ijebo.20180602.13

Received: October 22, 2018; Accepted: November 29, 2018; Published: December 11, 2018

\begin{abstract}
This thesis enhances the competitiveness of e-commerce by studying overseas warehousing and then supplements the existing research theories of global e-commerce. First, this paper summarizes the development of cross-border e-commerce and overseas warehousing supply chain models. Secondly, it analyzes the current situation of e-commerce global market scale and analyzes the characteristics of China's e-commerce market. In the second chapter, the research background of e-commerce and its impact on supply chain management is introduced. The Internet revolution has brought fundamental changes to the company's business and strategy. It also spawned a new sales model called "e-commerce" or "electronic trading." In addition to the more complex global concepts of more complex, more efficient, and more preferred customers, companies need to improve service quality and should be able to maintain lower operating costs in order to maintain market competitiveness. In addition, this article also discusses another area of expansion of e-commerce - cross-border e-commerce. Cross-border e-commerce is an online sale of products through retail channels or other countries' e-commerce platforms, without the need to go to that country in the field, it has certain advantages. Finally, the discussion goes into e-commerce, proposes to establish an overseas warehouse model, shorten delivery time, and improve the competitiveness of Chinese e-commerce in developed countries.
\end{abstract}

Keywords: Oversea Warehouses, Cross-Border E-Commerce, Competitiveness

\section{Introduction}

The internet revolution has led to a fundamental Delta of the company's operations and strategy. This has also spawned a new way of selling E-commerce via e-commerce.

In addition to the practical concept of globalization, clients are more intelligent, have more advantages and advantages, the industry is under an obligation to improve the quality of service and to maintain a lower operating Cost to maintain market competitiveness.

As a result, the Company is now considering Cost, quality, technology and other competitive advantages as a globally competitive environment for the strategy. With the advent of E-commerce, the most effective way for companies, shops, retailers and businesses is to maintain efficiency in supply chain management practices.

Due to the growing importance of supply chain management and supply chain management to managers and policymakers, many researchers and scholars have entered into this field.
As a result, many of the research articles in this subject have been completed. This field changes from the development of the Internet revolution and is now talking about e-supply chains. Some scholars affirm the management of supply chain and provide important and dynamic marketing companies. Nevertheless, academics and some companies are actually interested in warehouse management and implement new chain models by implementing overseas warehouses.

Although supply chain management is not well known, we have made significant research on importance and practicality in order to obtain a competitive advantage in order to obtain a competitive advantage. Overseas warehouse concept is very novel and rapid development. Therefore, there are very few research documents in overseas warehouses, only a few documents are concentrated in developed countries. Therefore, in the article, we seek to seek a theoretical shortage by improving the competitiveness of e-commerce by seeking the location of overseas warehouses to supplement this direction. [1] 
As mentioned above, most supply chain management studies to relate only to developed countries. Accordingly, the E-commerce supply chain management related to this paper is relatively small, especially in developing countries. Indeed, as the economic market in developing countries grows, developing countries are attracting more and more TNCs and Cost. The author thinks, must carefully study supply chain management, better solve this important Emerging market. The purpose of this study is to analyze the E-commerce market of developing countries and establish a new cross-border E-commerce supply chain model through overseas warehousing.

\section{Literature Review}

\subsection{E-commerce}

\subsubsection{E-Commerce Definition}

There is no standard definition for e-commerce. For example, there are various designations such as electronic business, e-commerce or EC. Briefly, the Oxford dictionary defines e-commerce as "conducting commercial transactions on the Internet electronically". Wikipedia defines e-commerce as "online purchase or sale transaction". Electronic commerce utilizes technologies such as mobile business, electronic fund transfer, supply chain management, Internet marketing, online transaction processing, electronic data interchange (EDI), inventory management system, automatic data collection system.

E-commerce is done between companies, homes, individuals, governments, and other public or private organizations. Include network, external network or order for electronic data exchange. [2] Type is defined by order. These do not include orders for telephone, fax, or manual printing of e-mails.

\subsubsection{Type of E-Commerce}

There are various types of e-commerce, and in the future new e-commerce will be possible. However, the following are the most commonly used in the world.

(1) B2B: Business enterprise, that is, transaction between companies. Example: Transactions between manufacturers and retailers, manufacturers and wholesalers.

(2) B2C: A business is a transaction between a consumer, an electronic commerce company and an individual consumer. Example: A retail store or a manufacturing company selects an online selling route close to a consumer.

(3) C2C: Transactions between consumers and individuals. This includes online bidding platform (Taobao) and online sales.

(4) SIPG: Business-to-government B2B transactions are similar, in which case the government's party is the subject of the government, for example, the government will purchase E-commerce in the public environment.

These four are the most notable E-commerce, but in 2015, this report submitted a new form of E-commerce to consider at trade conferences.

(5) Co-operative inter-organizational deals are self-government associations that are willing to cooperate voluntarily to achieve common objectives.

\subsection{Location-Allocation Problem}

\subsubsection{Warehousing}

The supply chain is important to the warehouse of the company. As a suitable tool, it can reduce shipping Cost and make the product closer to business partners through higher quality products and needs of Consolidation. A warehouse is a commercial building, usually considered a large flat building where manufacturers, importers, customs or wholesalers are stored in Inventory. Therefore, warehouses should be fully automated. [3] In an automated warehouse, tracking of goods is coordinated with the Warehouse Management System (WMS), this is a computer program of the database drive. Logistics personnel will use WMS to maintain accurate inventory levels, improve warehouse efficiency, and consider warehouse transactions and guidance methods. [4]

The latest developments in marketing have led to the development of the design style of the warehouse, which is enough to cause the warehouse to be used in warehouses and retail stores. These warehouses are highly heavy-duty industrial goods shelves, sold warehouses at the bottom of the shelf and usually placed at the top of the Inventory.

The manufacturer is dealing with the development of retailing outlets in specific regions and countries. These concepts reduced the final Cost to the Consumption of the product and the improved production sales ratio. Warehouse concept is a tool that avoids direct contact with the Consumption to manufacture an enterprise or contact an importer or another intermediate mechanism.

\subsubsection{Why a Warehouse}

Now, as the Internet revolution, some companies are trying to solve the existence of the warehouse. The warehouse problem is called a hot topic. From JC Cooper, he issued alternative warehouse alternatives, and the warehouse occupies one major shipping cost. [5]

The necessary function can be obtained by defining a given warehouse. Typically, the original function of the warehouse is to sell the product and sell it. After this, with the development of the supply chain, Cost is reduced in order to buy and sell orders to provide better services for business partners, and some companies and manufacturers have increased other activities in the warehouse. It seems to be assembled.

In general, the main objectives of warehouses and other facilities are as follows. That's because they don't always get better in sync. It has provisions providing a product that matches supply and demand with surprising fluctuations. The warehouse can achieve small, large cargo, transport target flow integration opportunities.

\subsubsection{Warehousing Costs}

The cost of the General management relates to the cost of the cubic English size and the available space of the basic 
facilities. It also includes various safety equipment (e.g. safety alarm, car ID) fees.

This cost includes costs incurred by external vendors allocating fares. This fee includes fuel costs, premiums and shipping truck costs. [6]

The manual expense refers to the Cost of the execution of various operations in the warehouse, including the receipt of purchase, data relating to computer systems and warehouse responsibilities. We assign operating duties every day, such as management responsibilities and work.

Labor costs are also referred to as Inventory to maintain Cost and store and dispose of Cost generated by the product. Warehouse fees are also related to processing Cost and storage Cost

The storage Cost, processing Cost is the Cost of various operations and processes carried out by the warehouse (receiving, storing, selecting, packaging, transportation). If it relates to other Cost, it is included in the processing Cost.

\subsubsection{Types of Warehouses}

There are various types of warehouses, but their main functions and internal activity types are different. Here are some examples.

Raw materials and parts warehouse: close to the source and manufacturing point. With raw materials, Raw materials can be introduced to manufacturing and assembly processes.

Product Warehouse: Partially completed assemblies and components. The warehouse holds partially completed products and components at different locations on the production line and assembly line.

Finished goods warehouse: located near the production site. These sites typically maintain the Inventory and maintain the differences between the production plan and requirements, and the warehouse is also located near the manufacturer to facilitate full pallet flow and complete pallet discharge.

Delivery Center: The delivery warehouse accumulates products from each production point and transports the combination of goods to a common business partner. Typically, warehouses are located at heart of production sites and business partners. Product movement is represented by the number of complete trays or boxes and the number of complete boxes or damaged boxes.

Execute the warehouse and performance centers: Receive individual customers, send small orders and send them. Through this product, we send small orders to individual consumers (cases and education).

Local Warehouse: provide a quick response to the customer and close to the customer's position. These warehouses cater mainly to the customer's needs. For enterprises, this is enough to call a separate project that conveys the same content of your customers every day.

Key product customization activities include packaging, labeling, marking, normal price and return processing.

It is used to cross and transport mixed materials from a variety of sources receiving materials (tray from the tray).

Classification of warehouses based on the geographical area they serve: Focus on warehouses and distribution warehouses. [7]

Centralized warehouses: Centralization usually refers to the provision of services to specific business units that serve the entire company. The decision is in the position of the entire network. The main features of the centralized approach are control, efficiency, and good economy.

Advantages: Increase productivity through balance. Increase the available knowledge. Tying products. Use the production process. Control System. Traffic consistency. Improve efficiency.

Not enough: An enterprise can't provide customers with the desire to get it automatically. This is only the intensive problem of certain market vendors and the structure of heterogeneous customers. Long-distance transportation routes within large central warehouses have high infrastructure costs. The process of policy decision making is gentle and inflexible. The initial cost is high. Bureaucracy in the system. bad temper. Dependent on the system.

\subsubsection{Retail Warehousing}

A retail warehouse is a new or modern use of the warehouse. Historically, since Toyota developed JIT technology, the traditional warehouse experienced a serious decline. However, due to market expansion, the distance to manufacturers and retailers has increased, and the market is expanding. As a result, each country or region of a company needs at least one warehouse to promote product clearing and supply chain flow. Because of this need, we developed a retail warehouse. Warehouses can be divided into different areas and in these areas, goods can be sold on a few and boxes can be boxed or stacked on top of another. In other words, companies offer two different services on the same warehouse floor: maintenance of goods and retail. [8]

\subsection{Warehouse Management System}

Warehouse management system is an important part of the supply chain. It mainly controls the storage and movement towards warehouse materials, processing trade, picking, transporting, picking and storing. WMS can teach real-time information on the box and optimize Inventory. Warehouse management system is applicable to automatic ID data acquisition techniques such as mobile computer, bar code scanner, radio, RFID, LAN. [9] In this process, collect data, real-time measurement, or wireless transmission to the central database. After that, the enterprise can accurately provide the status of the database goods. The main objective of WMS is to provide automated (computerized) procedures for the importation of goods. WMS provides useful links between logistics management and business instruction processing to extract products, parcels and shipping equipment.

\subsubsection{Warehouse Management System Advantages (Abbreviation WMS)}

WMS introduces a system that supports JIT environment to support the JIT environment by reducing Inventory movement and shortening the delivery time by reducing the 
accuracy of Inventory records.

Efficient warehouse utilization: warehouse management system can effectively utilize and receive, assemble, package and transport-related projects, effectively use warehouse space.

The document that reduces Inventory transactions: WMS maintains data to maintain data electronically, reduce documents relating to warehouse operations, such as receiving, selecting and packing, and ensuring timely and accurate delivery of information.

Improve Cyclicality count: WMS collects data and arranges personnel's Cyclicality count. These Cyclicalities may be used for planning purposes to improve the accuracy of Inventory records and minimize the higher effective Inventory.

Decrease the dependence on warehouse staff: You can standardize profitability by implementing WMS, and move Inventory and Inventory positions. These regulations can reduce the training Cost, reduce the error rate and maximize non-canonical practice.

Improve business partner services: through WMS implementations, streams can simplify the purchase orders to deliver, so the company can find the product exactly.

The actual date and availability of the release. WMS identifies and publishes delayed Inventory to minimize recovery and improve shipping accuracy. Improving productivity: intersections are another important aspect of the warehouse management system, where the purchase of goods approaches the station in order to obtain the location of the terminal, thus reducing the processing of the warehouse. To do this, WMS uses a material flow to optimize the cross-function optimization. WMS realizes the superiority over a range of Cost to the organization. WMS applied all advanced technology to the cost; Approximate price, improve warehouse activities and improve the efficiency of supply chain management. Therefore, we must implement WMS in accordance with several steps and control the Cost of WMS. [10]

\subsubsection{WMS and Supply Chain Management}

Warehouse management system is regarded as an important part of modern supply chain management. The immediate growth of the warehouse management system to market to demand is an important factor of maintaining and maintaining critical competitive advantages, as well as the consequences of significant Delta for the way the company provides funds, as well as the Acquisition of the warehouse management system. The main purpose of the sales and logistics system is to improve customer service, to further reduce the Cost of the market sector and to reduce the Cost of each market department. With the immediate (JIT), supply chain management (SCM), fast response (ATR) and effective Consumption response (EF), some of the concepts we follow is improving their performance, very careful, automated or mechanistic material transport solutions, more flexible, A number of important functions in the warehouse are mass production manufacturing or destruction. Integration center, cross-center, transfer, product realization center, warehouse, some other characters, customer support, installation, maintenance services. These concepts tend to grow in warehouses, such as the role and agility mentioned here, delayed production and reduced time. [11]

\subsubsection{Role of a Warehouse in the Supply Chain}

The customer's Inventory retention and service are an important warehouse function, which means that customers play an important role in the supply chain of the warehouse. A number of important functions of the warehouse are mass production manufacturing or destruction. Integration center, cross-center, transfer, product realization center, warehouse, some other characters, customer support, installation, maintenance services and so on. In these concepts, warehouses are often growing, such as the role and agility mentioned here, delaying production and reducing time. Therefore, the warehouse of the modern supply chain has an important function.

\section{E-Commerce Market Analysis}

The purpose of this chapter is to summaries the E-commerce market and briefly introduce the status of E-commerce in China and the developed countries. The following is the basic present situation of the E-commerce market, and the present situation of the research E-commerce market can better understand the two geographic locations of the study topic in this paper.

\subsection{E-Commerce in China}

\subsubsection{Uniqueness of the Business-to-Consumer Through Local E-Commerce Platform}

China is regarded as the king of the world E-commerce. In China, the network market experienced very rapid development and brought new business opportunities. In fact, China's E-commerce is considered one of the most promising companies and is thought to be the world's largest Consumption. China's E-commerce market is growing at a very fast pace, and has also experienced rapid development. Many companies and retailers in other parts of the world run their online business independently on their websites. In China, many retailers and big companies collect shops on E-commerce platforms. [10] For this platform, Alibaba's company calls it $75 \%$ of the "Consumption of tmp.com website". Amazon's market share is estimated at $26 \%$ in the U.S. e-commerce market in 2015 , according to a study by Mac. The Chinese E-commerce's characteristics directly affect the interdependence of Alibaba and the Consumption's online shopping experience. Electronic traders are also good at the same time. Because e-retailers who offer this product are well-known brands in a new product or market, any customer can find all available products in the market, no matter where they are, some even buy at the manufacturer's home. In addition, the characteristics of the Chinese network buyers and the factors purchased from these E-commerce platforms (tabao.com) are very important. In China, internet 
buyers rely on product recommendations and other suppliers' review, mostly on mobile phones. There is no regional restriction on online shopping, and even remote controllers can enjoy the family's delivery services. [12]

\subsubsection{Limits of E-Commerce in China}

China's E-commerce is still in its infancy and has experienced rapid growth. It is therefore important to the market to be in-depth understanding and careful study of competitive markets. Because China's E-commerce includes not only advanced cities but also advanced regional, customer satisfaction and taste are different. These ratings may threaten any electronics retailer. The system may reduce the Cost rates and critical work of online buyers in the PRC, and are therefore not satisfied with the potential for your business to be fatal. The Chinese logistics customer pays attention to the Cost and loss risk of delivery of goods and takes note of the delivery time and actual situation of the goods. As shown in Figure 1, the number of parcels issued by China in September 2018 represents $67.86 \%$ s of the world. There is a reason to believe that the establishment of overseas warehousing reduces international postage, there by reducing the cost of the company's Consumption or Consumption.

Each country's sending parcel amount in 2018-09
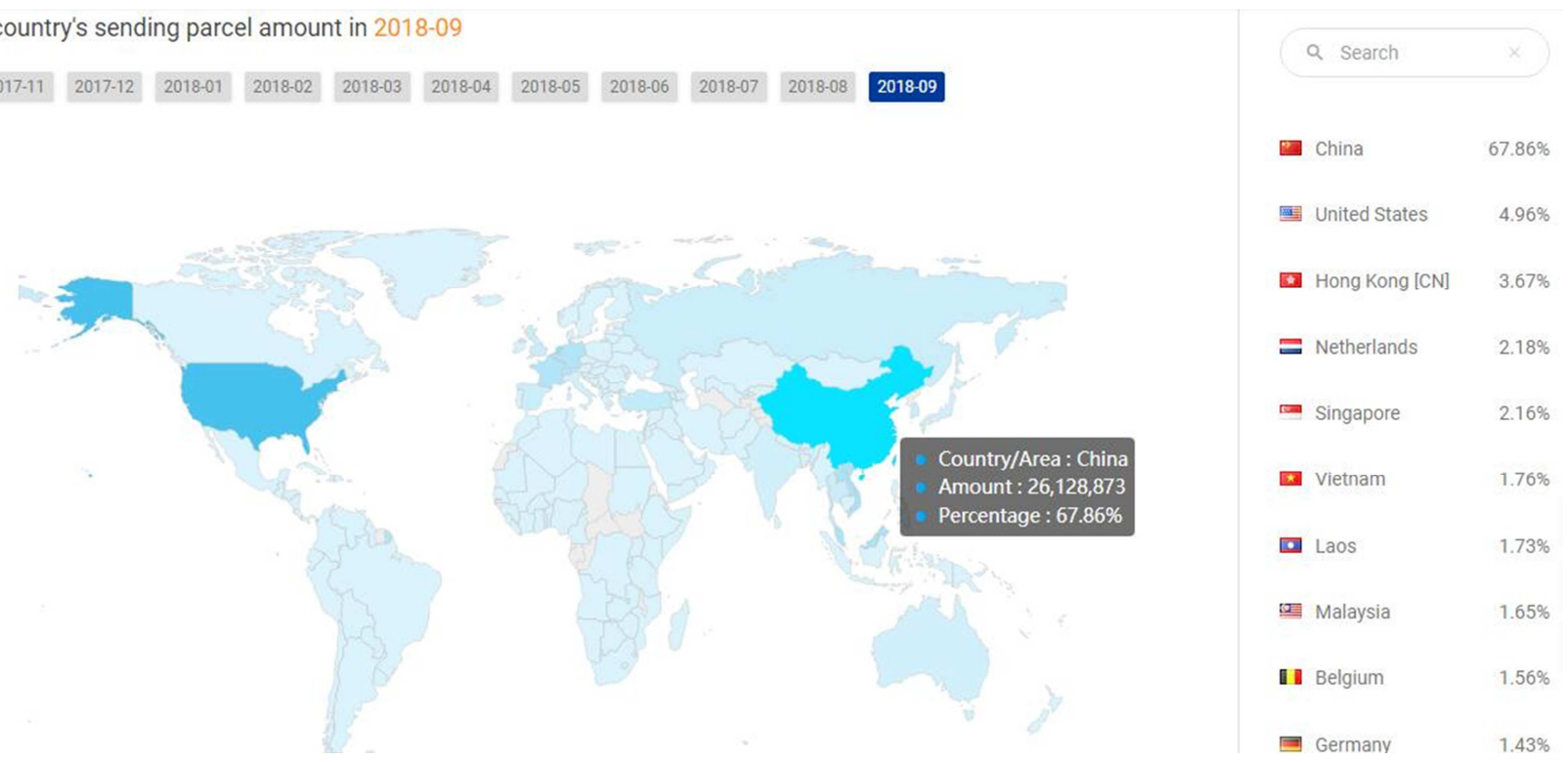

Figure 1. The proportion of parcels issued by China in the world in the past year.

\subsection{E-commerce in the Developed Countries in the United States as an Example}

In the United States, from an application perspective, the development of the Internet can be divided into three phases: the first phase is the email phase of the 1970s; the second phase, the information release phase, began in 1995. At present, the Internet is indeed the main application; in the third stage, the e-commerce stage (EC) is currently in a favorable position in the United States. Currently, EC applications will become the ultimate commercial use of the Internet. The three applications generated in the above three phases were told to develop at an alarming rate. The average flow of email has increased several times a year and has largely replaced traditional letters, calls, and faxes. The information distribution system represented by WEB technology has replaced the press release functions of some newspapers, radio stations, and TV stations. Almost all-important newspapers have a free electronic version. Because the Internet can make full use of and save social resources, the US government spares no effort to promote the popularity and development of the Internet. For example, when Internet business activities are still insufficient, the government pays for the Internet to run free of charge until the Internet is up and running in recent years, and can be benign. In order to cultivate the habits and environment of shopping on the Internet, various government departments require that no less than 4.5 million items are purchased on the Internet in 1997. In May 1997, the US government announced a policy, the Internet Tax Zone (Internet Free Zone). The policy stipulates that on the global scale, goods purchased and sold through the Internet are not taxed, including tariffs and commercial taxes. The policy has received varying degrees of support from Canada, Japan, Europe, and other countries. Therefore, the Internet Free Trade Zone can become the world's largest free trade zone, which is extremely broad and far-reaching. The field of application and scale of e-commerce in the United States is far ahead of other countries. Many large companies use the Internet to expand their business. [13]

Recently, Forrester Research released a report called "US E-Commerce: 2015-2020" to forecast and analyze online retail and online shopping trends for the next two to three years. Forrester expects US online retail sales to increase from $\$ 572$ billion in 2015 to $\$ 929$ billion in 2020 , maintaining an average annual growth rate of $14 \%$. E-commerce will account for $13 \%$ of total US retail sales. In all online sales, Figure 2 shows the proportion of parcels received in the United States in the past year. Online travel is still the largest online retail industry, online retailers continue 
to grow, and consumers shop online.

* Each country's receiving parcel amount in 2018-09

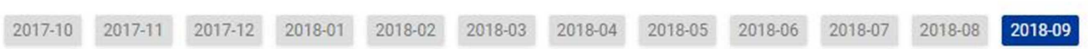
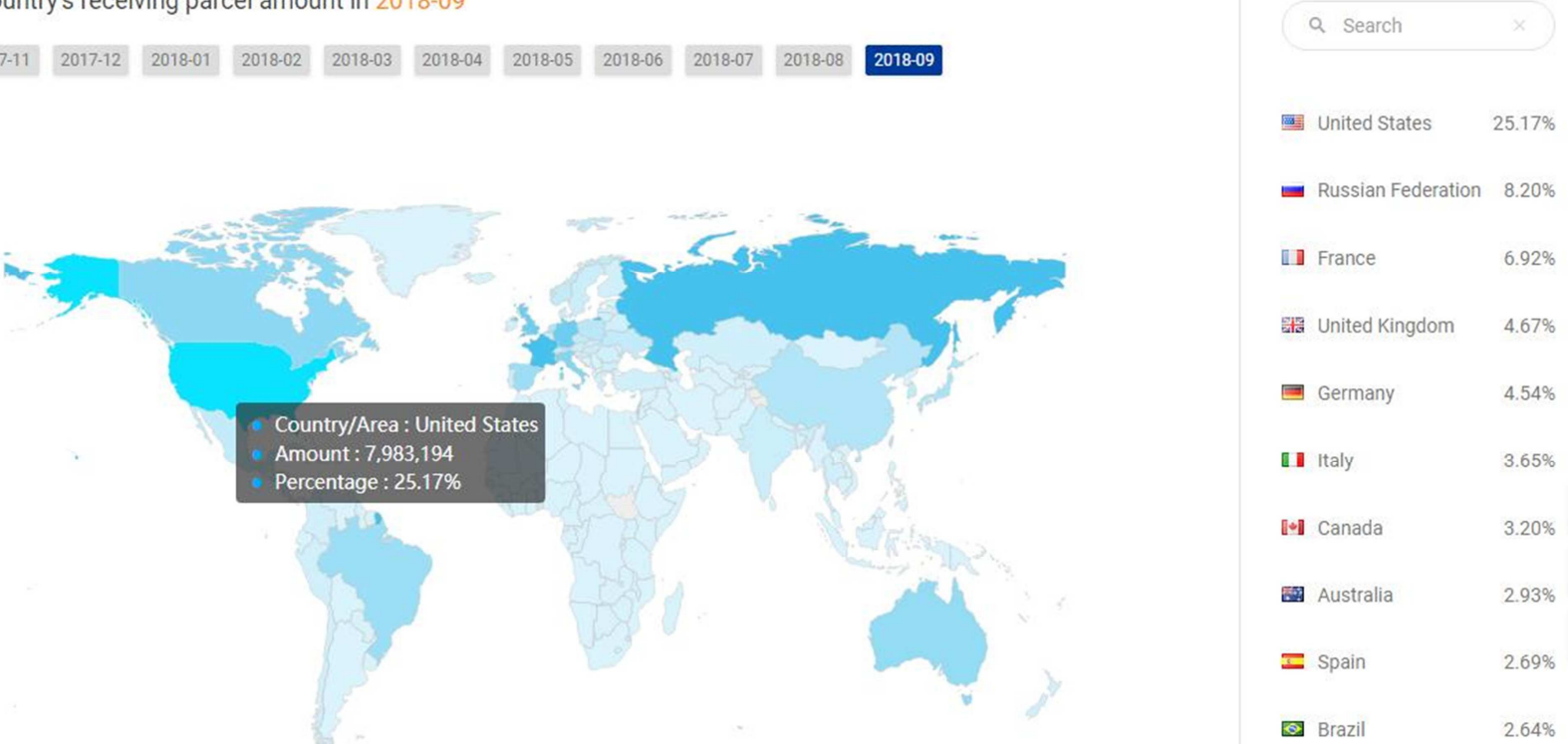

Figure 2. The proportion of parcels received in the United States in the past year in the world.

\subsection{Cross-Border E-Commerce}

When the Consumption is shopping from other jurisdictions and jurisdictions, the international E-commerce is referred to as a cross-border E-commerce. The sharing of common language and borders or online transactions between Consumption and suppliers using the same currency does not always assume that Consumption cross borders.

Most developing countries and economic institutions in transition are unlikely to assess trends, as official statistics and comparative statistics on E-commerce are lacking. According to available data, cross-border transactions are more important than developed countries in developing economies, and in many developed countries, all E-commerce transactions are applicable to domestic business partners. Many factors restrict E-commerce. For example, reliability and long-term transportation time and logistics, high transport Cost, do not want to use online payment, delivery and price list Price lack transparency.

February 31 Global Cross-Border E-commerce

An increased from E-commerce may be explained by the presence of a global platform provider, a Bonds between the seller and the buyer. When Alibaba, China's E-commerce giant, released its New York Stock Exchange at 2014, Alibaba's first market capitalization surpassed \$20 billion, making it the world's largest 20 companies. 2013, Alibaba has 2.31 billion activists, buy 49 times each year, exceed the 11 billion. Today, online people should be able to buy and sell products and services around the world.

Therefore, E-commerce can benefit from transactions in developed countries from the global market.

\subsection{Barriers to International E-Commerce}

Many areas of E-commerce face many challenges. Global e-retailers need to understand the polarity and cultural differences in their regional suppliers. Online buyers tend to forget the distance between geographic locations and often have high expectations of logistics and time expected expectations. Cost is a good element to determine the Consumption. Free or cheap postage has attracted much Consumption. Language is another important driving factor after geography (common boundary). Common language and culture reduce barriers and save costly transaction costs associated with retailers and Marketing. The Consumption wishes to pay in functional currency. The global deployment requires multi-currency conversion and settlement of the currency of the plan definition of the primary card. The bank must be A global payment solution provider for regional cooperation partners with Bankcard payments has earned online sales technology, partner innovation, and law, and shopping is one of the security payments you manage through a gateway management transaction.

\section{Establish an Overseas Warehouse}

Develop the location-allocation model, reduce time delivery, and improve the competitiveness of China's e-commerce in developed countries.

\subsection{Warehousing Cost}

Over the past few years, China has experienced a wave of commodity markets and the economic slowdown. This affects not only China but also the world. The influence of the commodity market and economic trend has also profoundly affected enterprises and customers' understanding of overseas warehouses.

In the solution Cost of warehouses around the world. First of all, understand our solution, overseas warehouse construction, Chinese company already has a certain overseas warehouse experience. However, in order to continue to 
maintain and improve overseas warehouses, there are four types of warehouse Cost to optimize the processing of overseas warehouses. [14]

Processing Cost: all Costs related to the product warehouse

Storage Cost: When the product changes, the storage Cost will not be generated.

Service Management: This cost is supported by the delivery center.

General management Expense: the expense not paid to the designated distribution center.

\subsection{Labor Costs}

A second factor that needs to be implemented abroad is the need for labor for its construction. Therefore, in order to repair the overseas warehouse, the enterprise must consider the wages Price of labor in the storage warehouse,

Obviously, compared with domestic labor Cost, the American labor force is higher than that of China. According to the full statistics, the Price of the American Express was three times the country's labor Price.

\subsection{Conclusion and Suggestions}

Using advanced economic institutions, such as the implementation of overseas warehouses in the United States, has become an inevitable requirement for the development of E-commerce in developing countries. The factors required for overseas warehouses are as follows:

More competitive markets in developing countries

Intense competition between China's domestic market and developed economic market

The high demand for emerging internet users and E-commerce is developed countries

Competitive advantage "The economic market can be provided by E-commerce in the Chinese border and offer better service to Price as usual." in developed countries

In comparison with China, Cost and issues from the United States and other developed countries will be implemented.

First, the land Cost of the U.S. transport overseas warehouse is the same as that of the Cost owning the local warehouse in China. By sharing construction Cost of other companies or Investment, investing in local partners, enterprises can reduce Cost in other ways. By leasing overseas warehouses, enterprises can also significantly reduce Cost. However, this means that enterprises can find enough warehouse leases through the national and Investment, Investing networks. [15]

Cross-border E-commerce and overseas warehouses are new themes of supply chain and trade. Therefore, compared with traditional business and supply chain model, the literature research of this subject is less. The study highlighted the transport and delivery of E-commerce in developed countries, such as China and the United States. [16] The preliminary objective of this paper is to reduce the transport and delivery of E-commerce between China and the developed countries. And deliver solution solutions to overseas warehouses in developed countries. The proposal considered factors such as warehouse Cost, artificial Cost, and location.

\section{Conclusion}

This paper studies the development of cross-border E-commerce and overseas warehousing supply chain model in China and developed countries. The research results can help companies enter overseas and establish warehousing. In the literature review, first, what is to explain what is overseas warehousing warehouse, at the same time driving across enterprises will focus on this area of research. The development of cross-border E-commerce and overseas warehousing supply chain model is summarized. Secondly, the present situation of the global market scale of E-commerce is analyzed. Of course, the key analysis is the characteristics of the Chinese E-commerce market. The interaction between E-commerce and supply chain management in supply chain management is the significance of E-commerce and supply chain management. E-commerce has developed steadily worldwide but has developed rapidly in China. The uniqueness of China's E-commerce is surprising. mainly because the giant's e-commerce platform mainly affects the behavior of Alibaba Group and Chinese customers. This booming market attracts many companies and retailers to compete fiercely and brutally. Secondly, the research background of E-commerce and its influence on supply chain management is introduced. The Internet revolution brought a fundamental Delta to the company's business and strategy. It also spawned a new sales model called "E-commerce" or "Electronic transactions.", which, in addition to the more complex, efficient and more complex global concepts of customers, needs to improve the quality of service and maintain a lower operating Cost to remain competitive in the market. In addition, new players from abroad enter the game and begin to gain advantage and improve their Market share. In fact, there is no geographical restriction on the internet. In this paper, another area of the E-commerce of E-commerce is discussed in this paper. Cross-border E-commerce is a country with a certain advantage through online sales of products of retail channels or E-commerce platforms in other countries without entering into the field. At last, the establishment of E-commerce was discussed, and the establishment of overseas warehouse model was putting forward, and the delivery time was shortened, and the competitiveness of China's E-commerce in developed countries was improved.

\section{Acknowledgements}

First of all, I thank my teacher Jin Hong for my teaching and guidance, and in the process of writing this paper, my teacher gave me a lot of help and heart guidance. The teacher 's strict way of doing work, wide knowledge, and the charm of a person' s personality will deeply affect me.

Also, the academic leaders and teachers are grateful for their support and encouragement to us. Because you are there, 
I can enjoy studying and growing at this time.

Of course, I am grateful to everyone that has walked together in the last two years, I thank my friends, I will enrich myself and enrich myself by interacting with each other. So, I would like to express my gratitude to everyone that made efforts in my guidance teacher once again.

\section{References}

[1] Aiba, Y. Hatano, N. and Takayasu, H. (2002) 'Triangular arbitrage as an interaction among foreign exchange rates', 310 , pp. 467-479.

[2] Blauwens, G. Baere, D. \& Voorde, V. d., 2010. Transport Economics. Antwerp: De Boeck.

[3] JC. C. \& Davis. M. 1984. Why have a warehouse? Retail and Distribution Management.

[4] Chiang, W. Y. K. Chajed, D. \& Hess, J. D., 2003. Direct Marketing, Indirect Profits: A Strategic Analysis of Dual-Channel Supply-Chain Design. Management Science.

[5] Dangayach \& Deshmuck, 2003. Evidence of manufacturing strategies in Idian industry: a survey. International Journal of Production Economics, Volume 83, pp. 279-298.

[6] Gevaers, Voorde, V. d. \& Vaneslander, 2009. Technical process innovations in green logistics: opportunities, barriers and best practices by using case studies. Brussel VUBPress.

[7] Hakimi, S. (1965) 'Optimum distribution of switching centers in a communication network and some related graph theoretic problems.' Operational Research. doi: 10.1007/978-3-319-13111-5.
[8] Kuehn. A. a. and Hamburger. M. J. (1963) 'A Heuristic Program for Locating Warehouses'. Management Science, 9(4), pp. 643-666. doi: 10.1287/mnsc.9.4.643.

[9] Laseter. T. M, Rabinovich E. K, Boyer, K. \& Rungtusanatham, M. J., 2007. Three critical issues in internet retailing. MIT Sloan Management Review.

[10] Mollenkopf, D. A, Rabinovich, E, Laseter, T. M. \& Boyer, K. K., 2007. Managing internet returns: A focus on effective service operations. Decision science.

[11] Gan Yining. Thoughts on the Status Quo of Internet + Logistics Intelligent Warehousing System and Industry Development [J]. Logistics Engineering and Management, 2018, 40 (03): 15-16.

[12] Liu Rui. B2C cross-border e-commerce logistics mode operation and development path exploration [J]. Business Economics Research, 2018 (05): 104-106.

[13] Meng Liang, Meng Jing. Analysis of the Choice of Overseas Warehouse Models of Cross-border E-commerce Enterprises in China-Based on the Perspective of Consumer Goods Export Trade [J]. China Circulation Economy, 2017, 31(06):37-44.

[14] Deng Xiaoyi, Xing Yuanzhi. Research on overseas warehousing construction in China's cross-border e-commerce logistics [J]. Logistics Science and Technology, 2017, 40 (03): 130-133.

[15] Zhai Rongjiao. Research on overseas warehouse construction model in China's cross-border e-commerce logistics [D]. Anhui University, 2016.

[16] Zhang Kaiwang. Analysis of overseas warehousing of cross-border e-commerce [J]. Value Engineering, 2016, 35(02): 61-63. 